\title{
PRODUÇÃO FLORESTAL EM PROPRIEDADES RURAIS FOMENTADAS: ESTUDO DE CASO NO MUNICÍPIO DE DOIS VIZINHOS, PARANÁ
}

\author{
FOREST PRODUCTION IN FOMENTED RURAL PROPERTIES: CASE STUDY IN THE \\ MUNICIPALITY OF DOIS VIZINHOS, PARANÁ
}

Anathan Bichel ${ }^{1}$, Eleandro José Brun ${ }^{2}$

${ }^{1}$ Universidade Estadual de Londrina, Londrina, Paraná, Brasil - anathan_sulina@hotmail.com

${ }^{2}$ Universidade Tecnológica Federal do Paraná, Dois Vizinhos, Paraná, Brasil eleandrobrun.utfpr@gmail.com

\begin{abstract}
RESUMO
O fomento florestal é um instrumento estratégico que promove a integração dos produtores rurais à cadeia produtiva e lhes proporciona vantagens econômicas, sociais e ambientais. O presente trabalho teve como objetivo analisar o planejamento e a produção florestal em propriedades rurais fomentadas no município de Dois Vizinhos, Paraná. 0 programa de incentivo ao desenvolvimento florestal realizado pelo município em 2009 e 2010, contemplou 147 produtores com mudas de Eucalyptus spp., distribuídos em 33 localidades. Foram obtidas respostas de 86 participantes, 40 beneficiados com mudas em 2009 e 46 em 2010. A aquisição de dados ocorreu por meio de visitas e aplicação de questionários; relacionadas as características socioeconômicas do entrevistado, motivação em participar do programa, bem como informações das atividades silviculturais. Os dados foram analisados com ferramentas de estatística descritiva e teste qui-quadrado. Essa análise compreendeu, principalmente, a categorização dos entrevistados em dois grupos: os que adquiriram mudas em 2009 e os que adquiriram mudas em 2010. Os resultados mostram a existência de uma produção florestal de pequena escala, sendo realizada, sobretudo por agricultores familiares. As operações silviculturais foram realizadas utilizando de trabalho manual e pouco uso de mecanização. Os recursos utilizados, bem como os insumos, foram provenientes da propriedade ou estão disponíveis nas proximidades, a um baixo custo. A produção florestal sofreu com a falta de recursos e serviços especializados; o que levou a tomada de decisão baseada na estrutura física e organizacional de outras atividades agrícolas.
\end{abstract}

PALAVRAS-CHAVE: Atividades florestais, Fomento florestal, Uso da terra.

\begin{abstract}
Forestry foment is a strategic instrument that promotes the integration of rural producers into the chain and provides social and environmental advantages. The objective of this work was to analyze the planning of forest production in rural properties promoted in the municipality of Dois Vizinhos, Paraná. The incentive program for forestry development carried out by the municipality in 2009 and 2010, included 147 producers with seedlings of Eucalyptus spp., distributed in 33 locations. Responses obtained from 86 participants, 40 benefited from seedlings in 2009, and 46 in 2010. Data acquisition occurred through visits and application of questionnaires; related to the interviewee's socioeconomic characteristics, motivation to participate in the program, as well as information on silvicultural activities. The data analyzed with descriptive statistics tools e and chi-square test. This analysis mainly comprised the categorization of respondents into two groups: those who purchased seedlings in 2009 and those who purchased seedlings in 2010. The results show the existence of small scale production, being carried out, mainly by family farmers. The silvicultural operations were carried out using manual labor and little use of mechanization. The resources used, as well as the inputs, came from the property or are available nearby, at a low cost. Forest production suffered from a lack of resources and specialized services; which led to decision-making based on the physical and organizational structure of other agricultural activities.
\end{abstract}

KEYWORDS: Forestry activities, Forestry foment, Land use. 
incentivos, por meio de programas de fomento, visam o desenvolvimento da cultura em uma determinada região, o abastecimento de pequenas e médias indústrias, de abrangência microrregional, passando por programas voltados ao abastecimento estratégico de determinada matéria-prima para o setor agroindustrial, de abrangência nacional, até atingir escala global (SIQUEIRA et al., 2004).

A parceria entre empresas e/ou órgão públicos e a comunidade, através de programas de florestas, proporciona o ingresso do pequeno produtor rural na atividade florestal, a racionalização do uso da terra e democratização de alternativas de renda (RIBEIRO \& MIRANDA, 2008).

O setor público se tornou um importante agente incentivador no estabelecimento de programas de reflorestamento para produtores rurais (BASSO et al., 2012). Eisfeld et al. (2017) destacam as principais premissas na visão dos órgãos públicos: 1) necessidade de implantar florestas artificiais para suprir a demanda de consumo de madeira; 2 ) criar a possibilidade da oferta pelo produtor rural de matéria-prima de origem florestal; 3) promover o recobrimento arbóreo das áreas ociosas de pequenas e médias propriedades rurais; 4) gerar um aporte de renda adicional na economia familiar; e 5) diversificar a produção no meio rural.

O conjunto das condições que favorecem 0 desenvolvimento da silvicultura associado às políticas de incentivos fiscais caracteriza-se como a contribuição mais consistente para o desenvolvimento de bases florestais (FISCHER \& ZYLBERSZTAJN, 2012). Segundo Fontes et al. (2003) o papel importante que as florestas desempenham para a sociedade justificam a elaboração de políticas públicas de incentivos a plantios florestais.

Para que as florestas plantadas atinjam o mercado consumidor, há necessidade de considerar o planejamento das técnicas silviculturais a serem empregadas: escolha da espécie, do espaçamento, do preparo do solo, adubação ou fertilização, plantio propriamente dito, replantio, tratos culturais de manutenção, entre outros. Com base nesses pressupostos, objetiva-se, com este trabalho, analisar o planejamento da produção florestal em propriedades rurais fomentadas no município de Dois Vizinhos, Paraná.

\section{MATERIAL E MÉTODOS}

O trabalho foi realizado no município de Dois Vizinhos, sudoeste do Estado do Paraná. O município está localizado no terceiro planalto paranaense, com altitude média de $520 \mathrm{~m}$, nas coordenadas centrais de $25^{\circ} 74^{\prime} \mathrm{S}$ e $53^{\circ} 06^{\prime} \mathrm{W}$.

$\mathrm{O}$ programa de incentivo ao desenvolvimento florestal realizado pela prefeitura municipal de Dois Vizinhos, em 2009 e 2010, contemplou 147 produtores rurais, distribuídos em 33 localidades, com mais de 300 mil de mudas de Eucalyptus spp. A aquisição de dados foi realizada a partir da aplicação de questionários contendo questões abertas, semiabertas e fechadas. As questões estavam relacionadas as atividades silviculturais e de manejo florestal (Quadro 1).

Quadro 1. Tópicos abordados junto aos participantes.

\begin{tabular}{|l|}
\hline \multicolumn{1}{|c|}{ Tópicos } \\
\hline Área da propriedade e área com eucalipto \\
Local de implantação (em toda a propriedade e ou em parte \\
da mesma) \\
Situação do local (em encosta, área abandonada, pastagens, \\
lavoura, outra) \\
Espaçamento adotado ou recomendado \\
Limpeza de área (manual, mecanizada, química) \\
Tipo de preparo do solo (coveamento, aração, gradagem, \\
escarificação, outro) \\
Plantio (imediato ou outro momento); Mês de plantio; \\
Monitoramento de pragas (semanal, outro) \\
Replantio; Motivos de replantio; Número de vezes que \\
realizou o replantio \\
Adubação; Tipos de adubação \\
Tratos culturais de controle de invasoras; número de vezes \\
que realizou; Tipo de trato cultural \\
Desrama ou desbaste \\
Realizou desbaste ou corte raso \\
\hline
\end{tabular}

A pesquisa de campo ocorreu em 2012-2013. Do total, obtivemos 86 respostas (40 respostas de beneficiados com mudas em 2009 e 46 de beneficiados em 2010). Vale ressaltar que alguns participantes (61) não responderam às perguntas da pesquisa ou não foram localizados.

A categorização dos entrevistados ocorreu para dois grupos: os que adquiriram mudas em 2009 e os que adquiriram mudas em 2010. Utilizou-se de estatística descritiva para descrever e compreender os dados. Neste manuscrito, foi utilizado o teste qui-quadrado a nível de significância de 10\% (KHANAL et al., 2020). Os níveis de significância do qui-quadrado são comumente relatados com valores $p \leq 10 \%$, $\leq 5 \%$ e $1 \%$ (MARKOWSKI-LINDSAY et al., 2018). O teste exato de Fisher foi usado apenas quando havia menos de 5 observações em uma célula (na tabela de contingência) (COSTA et al., 2013). O software utilizado foi o programa estatístico R (versão 3.6.0; 2019).

\section{RESULTADOS}

O plantio de eucalipto foi realizado por dois perfis de 
participantes, os que produzem lenha para uso em suas próprias propriedades, principalmente na geração de calor com objetivo de autossuficiência energética e venda do excedente; e produtores florestais que visam diversos usos, vendendo a madeira para serrarias e para combustível.

A área média das propriedades visitadas por este estudo é $16,41 \pm 12,27$ ha nos produtores que adquiriram mudas em 2009 e 16,17 \pm 12,96 ha para 2010 (Figura 1a). As plantações provenientes do programa fomento ocupam uma área média de 0,91 \pm 0,71 ha (2009) e 1,06 $\pm 1,04$ ha (2010), como mostrado na Figura 1b. Os plantios de eucalipto foram efetuados, em sua maioria, em parte da propriedade (Tabela 1a), sendo áreas mais inclinadas antes ocupadas por pastagens, lavouras ou áreas abandonadas. Áreas nobres da propriedade são destinadas a culturas temporárias, outras culturas permanentes ou usadas como pastagens para gado leiteiro e bovino de corte. As florestas nativas ocupam aproximadamente 15 a $20 \%$ da propriedade, onde predomina o bioma Mata Atlântica. Mesmo estando em áreas mais inclinadas a maioria das propriedades possuem fácil acesso para realizar as atividades de manejo. A Figura 2 ilustra o uso típico da terra em pequenas propriedades familiares rurais sob diversidade de culturas e criação de animais.

Não houve diretrizes para o plantio de eucalipto, pois boa parte dos produtores realizaram as atividades por conta própria, sem assistência técnica de profissionais da prefeitura ou particular. Forte variação foi relatada para escolha do espaçamento; cerca de vinte e duas (22) opções diferentes $(P<0,01)$. Dos 40 plantios efetuados em 2009, a maioria, 11 plantios, adotaram o espaçamento $2 \mathrm{~m} \times 2 \mathrm{~m}$. O espaçamento $2,5 \mathrm{~m} \times 2 \mathrm{~m}$ foi o segundo mais utilizado em 2009, com 5 plantios. Assim como em 2009; em 2010, o espaçamento $2 \mathrm{~m} \times 2 \mathrm{~m}$ foi o mais adotado. Dos 46 plantios, 18 utilizaram este espaçamento. 0 segundo mais adotado em 2010 foi o espaçamento $2 \mathrm{~m} \times 2,5 \mathrm{~m}$ com 5 plantios (Tabela 1b).

As técnicas de limpeza de área foram adotadas por todos os participantes, mas diferiu significativamente entre os grupos $(P<0,1)$. $O$ predominante de limpeza de área foi a manual (mais de $80 \%$ dos participantes adotaram, em ambos os anos), seguida de limpeza mecanizada. Limpeza química foi adotada por apenas 2 participantes (Tabela 1c).

(a)
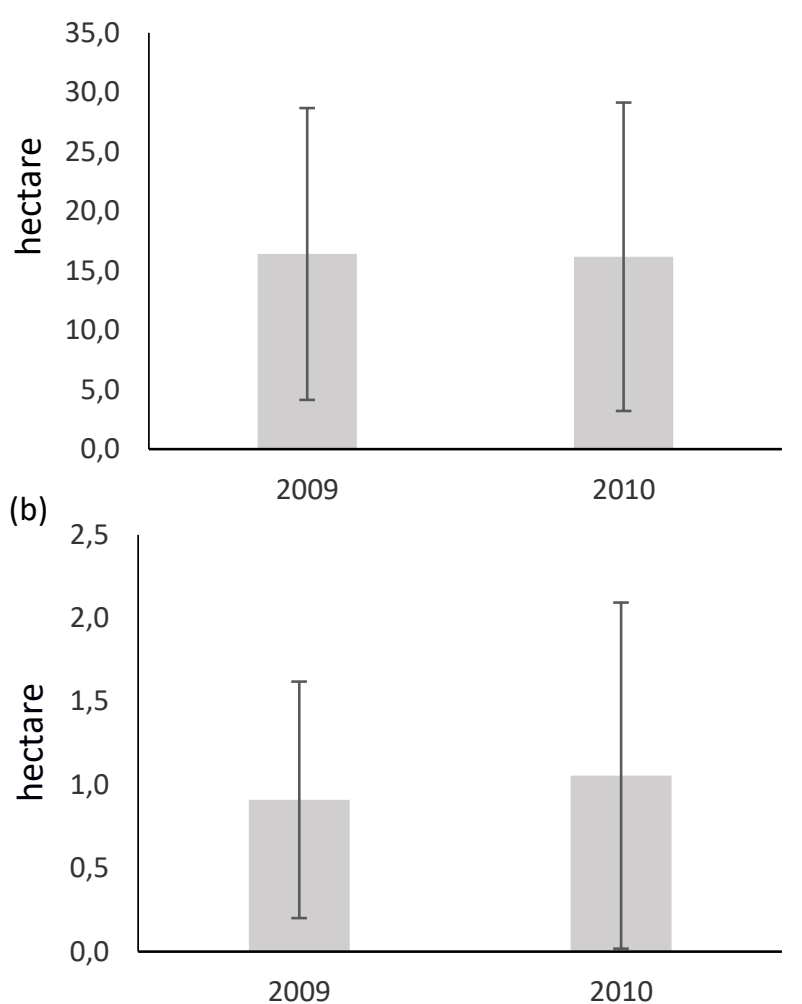

Figura 1. Área média das propriedades visitadas (a) e área média ocupada com eucalipto do programa de fomento florestal (b). Média ( \pm Desvio padrão).

Diferente da limpeza de área que todos os produtores adotaram, o preparo do solo (Tabela $1 \mathrm{~d}$ ) foi realizado por 62 produtores (31 em 2009 e 31 em 2010), utilizando de coveamento manual, aração, escarificação ou gradagem (Tabela 1e). Os demais produtores, utilizaram apenas de abertura de cova (leve abertura de sulco para deposição da muda).

A vistoria de pragas e doenças ocorreu semanalmente, pré e pós-plantio; no entanto nem todos os produtores a realizaram, sendo que dois (2) dos participantes de 2009 e dois (2) dos participantes de 2010 não realizaram a vistoria (Tabela 1h, 1i).

A correção do solo, foi realizada por $7,5 \%(2009, n=40)$ e 4,35\% $(2010, n=46)$ dos produtores. Já a adubação e a fertilização (Tabela $1 \mathrm{~m}, 1 \mathrm{n}, 10$ ), foram realizadas por 22 participantes do ano de 2009 e 23 de 2010. Destes, 37,5\% $(2009, n=40)$ e $32,61 \%(2010, n=40)$ realizaram apenas uma aplicação; 12,5\%: (2009, $n=40)$ e 13,04\% (2010, $n=46)$ duas aplicações e $5 \%(2009, n=40)$ e 4,35\% (2010, $\mathrm{n}=46)$ três aplicações. As práticas de adubação e ou fertilização ocorreram, em sua maioria, no plantio (32,50\%: 2009, $n=40$ e 28,26\%: 2010, $n=46$ ). As demais aplicações foram realizadas pelos produtores entre o primeiro e o 14 은 mês pós-plantio. 


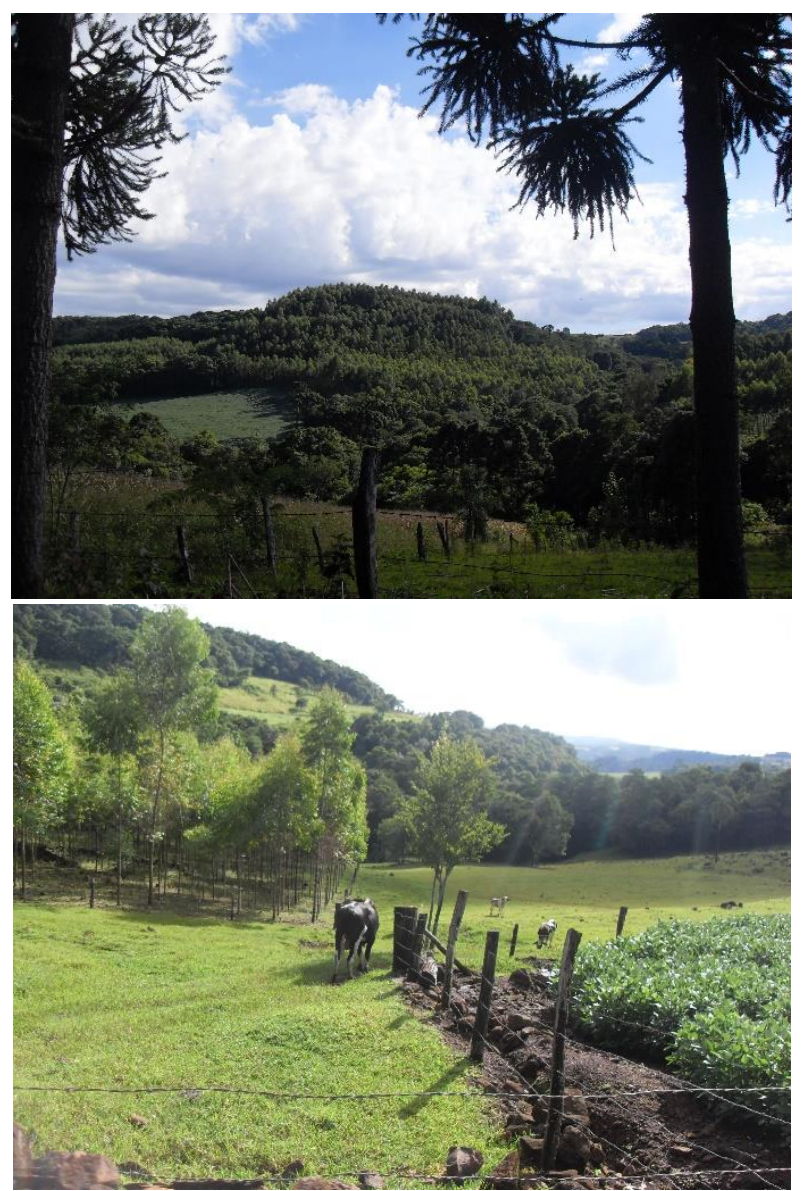

Figura 2. Uso típico da terra em pequenas propriedades familiares rurais sob diversidade de culturas e criação de animais. Fotografia: autores.

Apenas dois produtores de 2010 realizaram análise do solo; demais produtores seguiram recomendações ou aplicações padrões, sem critério estabelecido. O uso de "apenas adubação orgânica" no ciclo foi a mais empregada com $30 \%(2009, n=40)$ e $32,61 \%(2010, n=46)$. Fontes minerais foram adotadas por $15 \%(2009, n=40)$ e $10,87 \%$ (2010, $n=46$ ) dos produtores que realizaram algum tipo de correção, adubação ou fertilização; e ambas, adubação orgânica e mineral, ao longo do ciclo, foram utilizadas por $10 \%(2009, n=40)$ e 6,52\% $(2010, n=46)$.

A maioria dos plantios no ano de 2009 foram realizados no mês de julho $(30 \%, n=40)$ e, para 2010 no mês de setembro $(43,48 \%, n=46)(P<0,01)$. No entanto, foram citadas diferentes épocas de plantio; em 2009 variaram de maio a dezembro e, em 2010, de junho a novembro (Tabela 1g). Para marcação dos locais de plantio, A marcação de covas de plantio "a passo" foi o mais adotado (85\%: 2009, $\mathrm{n}=40$ e 58,7\%: 2010, $\mathrm{n}=46$ ), seguida do alinhamento (15\%: 2009, $n=40$ e 41,3\%: 2010, $n=46$ ). Todos os plantios foram realizados manualmente, tanto para 2009 quanto para 2010. A maioria dos produtores (77,5\%: 2009, $n=40$ e 78,26\%: 2010, $\mathrm{n}=46$ ) realizaram o plantio imediatamente (Tabela 1f), ou seja, logo após a retirada das mudas; demais produtores realizaram de três dias a dois meses após a retirada. A forma de armazenamento, antes de realizar o plantio propriamente dito, foi próxima a outras árvores, em sombras, sob regas constantes.

Dos participantes, 42,5\% em 2009 e 65,22\% em 2010 citaram replantios $(P<0,01$, Tabela $1 \mathrm{j}$ ); sendo que, em 2009 , tiveram produtores que realizaram de duas (15\%, $n=40)$ a três vezes $(15 \%, n=40)$. Em 2010, o mais citado foram os que realizaram apenas uma vez (Tabela 1I) o replantio $(30,43 \%, n=46)$. Houve produtores que realizaram replantios até 4 vezes. Os principais motivos (Tabela 1k) para o replantio foram: formigas cortadeiras e estiagem, em ambos os anos $(40 \%$ e $42,5 \%$ respectivamente para $2009, n=40$ e $41,3 \%$ e $45,65 \%$ para $2010, n=46)$. Foram citados ainda, ataque de outros insetos, animais domésticos (bovinos, equinos) e silvestres (tatu); e geadas. Não foram realizados plantios com polímeros retentores de água, ou outros produtos citados como "facilitadores de pegamento".

Os tratos culturais de controle de invasoras $(P<0,01$, Tabela 1p, 1q, 1r, 1s) foram realizados por $92,5 \%$ dos produtores beneficiados de 2009 e $100 \%$ dos produtores de 2010. O número de vezes que ocorreu a prática variou de uma a seis, com predominância da aplicação duas vezes $(30 \%, n=40)$ em 2009 e de duas a três vezes (ambas contribuíram com 30,43\%, n=46) em 2010. A operação variou de limpeza inicial até 24 meses após o plantio. Muitos produtores não se recordavam o período de realização, citando "conforme a necessidade".

Em 72,50\% ( $n=40)$ dos produtores adotaram a limpeza para a área total ao menos uma vez, ou seja, limpeza da entrelinha, coroamento, entre outros manejos dentro de um mesmo período preestabelecido; $55 \%(n=40)$ dos produtores adotaram ao menos uma vez, apenas a limpeza na entrelinha e $42,5 \%(n=40)$ apenas o coroamento das plantas; porém em épocas diferentes. Dos produtores de 2010, 56,52\% ( $n=46$ ) realizaram ao menos uma vez a limpeza em toda a área, $73,91 \%(n=46)$ realizaram limpezas na entrelinha e $45,65 \%(n=46)$ o coroamento de plantas. Os produtores de 2009 e 2010 utilizaram, em sua maioria, apenas o método manual de controle (60\%: 2009, $n=40$ e 56,52\%: 2010, $n=46)$, que consistia predominantemente na capina e roçada.

Dos produtores de 2009, que adotaram os tratos de controle de invasoras, o segundo método mais utilizado foi o controle químico $(22,5 \%, \mathrm{n}=40)$; enquanto que dos produtores de $2010,28,26 \%(n=46)$, citaram os métodos "manual e químico" (integrado). Apenas o método mecanizado, foi citado por $5 \%(n=40)$ dos produtores de 
2009 e 4,35\% ( $n=46$ ) de 2010; manual e químico em 2009 (5\%, $n=40)$ e controle químico em $2010(10,87 \%, n=46)$.

A desrama (Tabela 1t, 1u) foi realizada por apenas 17 produtores de 2009 e 22 produtores de 2010; destes, boa parte realizou apenas uma vez (32,5\%: 2009, $n=40$ e 32,61\%: 2010, $n=46$ ), no primeiro ano após o plantio; seguido de duas vezes (10\%: 2009, $n=40$ e 13,04\%: 2010, $n=46)$. Houve produtores que realizaram a desrama até três vezes (2,17\%: $2010, n=46)$, com idades variando de 3 meses a 18 meses. Não foram citadas intervenções envolvendo a colheita florestal até o período de avaliação da pesquisa.

Tabela 1. Práticas silviculturais adotadas pelos participantes do programa de fomento florestal em 2009 e 2010.

\begin{tabular}{|c|c|c|c|c|}
\hline \multirow[b]{2}{*}{ Variáveis } & \multicolumn{4}{|c|}{ Ano de participação no programa } \\
\hline & $\begin{array}{c}2009 \\
(n=40)\end{array}$ & $\begin{array}{c}2010 \\
(n=46)\end{array}$ & $\begin{array}{c}2009 \\
(\%)\end{array}$ & $\begin{array}{c}2010 \\
(\%)\end{array}$ \\
\hline \multicolumn{5}{|c|}{${ }^{\text {aLocal de implantaçãons }}$} \\
\hline $\begin{array}{l}\text { Em toda a } \\
\text { propriedade }\end{array}$ & 2 & 3 & 5,00 & 6,52 \\
\hline Em parte da mesma & 38 & 43 & 95,00 & 93,48 \\
\hline Total & 40 & 46 & 100 & 100 \\
\hline \multicolumn{5}{|c|}{${ }^{b}$ Espaçamento $(\mathrm{m} \times \mathrm{m})^{*}$} \\
\hline $0,5 \times 1$ & 1 & 2 & 2,50 & 4,35 \\
\hline $1 \times 1$ & 2 & 2 & 5,00 & 4,35 \\
\hline $1,5 \times 1,2$ & 0 & 1 & 0,00 & 2,17 \\
\hline $1,5 \times 1,5$ & 3 & 3 & 7,50 & 6,52 \\
\hline $1 \times 2$ & 1 & 0 & 2,50 & 0,00 \\
\hline $2 \times 1$ & 2 & 1 & 5,00 & 2,17 \\
\hline $2 \times 1,5$ & 2 & 3 & 5,00 & 6,52 \\
\hline $2 \times 2$ & 11 & 18 & 27,50 & 39,13 \\
\hline $2 \times 2,5$ & 1 & 5 & 2,50 & 10,87 \\
\hline $2 \times 3$ & 0 & 2 & 0,00 & 4,35 \\
\hline $2 \times 4$ & 1 & 0 & 2,50 & 0,00 \\
\hline $2,2 \times 1,6$ & 0 & 2 & 0,00 & 4,35 \\
\hline $2,5 \times 2$ & 5 & 0 & 12,50 & 0,00 \\
\hline $2,5 \times 2,5$ & 2 & 2 & 5,00 & 4,35 \\
\hline $2,5 \times 3$ & 2 & 0 & 5,00 & 0,00 \\
\hline $3 \times 2$ & 2 & 2 & 5,00 & 4,35 \\
\hline $3 \times 2,5$ & 1 & 1 & 2,50 & 2,17 \\
\hline $3 \times 3$ & 2 & 0 & 5,00 & 0,00 \\
\hline $3 \times 4$ & 0 & 1 & 0,00 & 2,17 \\
\hline $3,5 \times 2,5$ & 1 & 0 & 2,50 & 0,00 \\
\hline $4 \times 1$ & 1 & 0 & 2,50 & 0,00 \\
\hline $15 \times 1,5$ & 0 & 1 & 0,00 & 2,17 \\
\hline Total & 40 & 46 & 100 & 100 \\
\hline \multicolumn{5}{|c|}{ 'Limpeza de área*** } \\
\hline Manual & 37 & 39 & 92,50 & 84,78 \\
\hline Mecanizada & 3 & 5 & 7,50 & 10,87 \\
\hline Química & 0 & 2 & 0,00 & 4,35 \\
\hline Total & 40 & 46 & 100 & 100 \\
\hline
\end{tabular}

\begin{tabular}{|c|c|c|c|c|}
\hline \multirow[b]{2}{*}{ Variáveis } & \multicolumn{4}{|c|}{ Ano de participação no programa } \\
\hline & $\begin{array}{c}2009 \\
(n=40)\end{array}$ & $\begin{array}{c}2010 \\
(n=46)\end{array}$ & $\begin{array}{c}2009 \\
(\%)\end{array}$ & $\begin{array}{c}2010 \\
(\%)\end{array}$ \\
\hline \multicolumn{5}{|c|}{ dPreparo do solons } \\
\hline Sim & 31 & 31 & 77,50 & 67,39 \\
\hline Não & 9 & 15 & 22,50 & 32,61 \\
\hline Total & 40 & 46 & 100 & 100 \\
\hline \multicolumn{5}{|c|}{ eTipo de preparo do solons } \\
\hline Coveamento & 23 & 23 & 57,50 & 50,00 \\
\hline Aração & 7 & 7 & 17,50 & 15,22 \\
\hline Gradagem & 1 & 0 & 2,50 & 0,00 \\
\hline Escarificação & 0 & 1 & 0,00 & 2,17 \\
\hline Não realizou & 9 & 15 & 22,50 & 32,61 \\
\hline Total & 40 & 46 & 100 & 100 \\
\hline \multicolumn{5}{|c|}{ fPlantions } \\
\hline Imediato & 31 & 36 & 77,50 & 78,26 \\
\hline 10 a 15 dias & 3 & 5 & 7,50 & 10,87 \\
\hline 15 a 20 dias & 5 & 4 & 12,50 & 8,70 \\
\hline 2 meses & 1 & 1 & 2,50 & 2,17 \\
\hline Total & 40 & 46 & 100 & 100 \\
\hline \multicolumn{5}{|c|}{ gMês de plantio* } \\
\hline Maio & 4 & 0 & 10,00 & 0,00 \\
\hline Jun & 3 & 4 & 7,50 & 8,70 \\
\hline Jul & 12 & 7 & 30,00 & 15,22 \\
\hline Ago & 6 & 9 & 15,00 & 19,57 \\
\hline Set & 8 & 20 & 20,00 & 43,48 \\
\hline Out & 4 & 5 & 10,00 & 10,87 \\
\hline Nov & 2 & 1 & 5,00 & 2,17 \\
\hline Dez & 1 & 0 & 2,50 & 0,00 \\
\hline Total & 40 & 46 & 100 & 100 \\
\hline \multicolumn{5}{|c|}{${ }^{\text {hMonitoramento de Pragasns }}$} \\
\hline Sim & 38 & 44 & 95,00 & 95,65 \\
\hline Não & 2 & 2 & 5,00 & 4,35 \\
\hline Total & 40 & 46 & 100 & 100 \\
\hline \multicolumn{5}{|c|}{ 'Monitoramento de pragas ${ }^{\text {ns }}$} \\
\hline Semanal & 37 & 43 & 92,50 & 93,48 \\
\hline Outros & 1 & 1 & 2,50 & 2,17 \\
\hline Não realizou & 2 & 2 & 5,00 & 4,35 \\
\hline Total & 40 & 46 & 100 & 100 \\
\hline \multicolumn{5}{|c|}{ 'Replantio* } \\
\hline Sim & 17 & 30 & 42,50 & 65,22 \\
\hline Não & 23 & 16 & 57,50 & 34,78 \\
\hline Total & 40 & 46 & 100 & 100 \\
\hline \multicolumn{5}{|c|}{ kMotivo de replantio* } \\
\hline Formiga & 16 & 19 & 40,00 & 41,30 \\
\hline Estiagem & 17 & 21 & 42,50 & 45,65 \\
\hline Geada & 0 & 6 & 0,00 & 13,04 \\
\hline Outro & 5 & 7 & 12,50 & 15,22 \\
\hline Total $^{\#}$ & 38 & 53 & 95,00 & 115,22 \\
\hline \multicolumn{5}{|c|}{ 'Número de vezes que foi realizado o replantio* } \\
\hline 1 & 3 & 14 & 7,50 & 30,43 \\
\hline 2 & 6 & 9 & 15,00 & 19,57 \\
\hline 3 & 6 & 5 & 15,00 & 10,87 \\
\hline Mais de 3 & 2 & 2 & 5,00 & 4,35 \\
\hline Não realizou & 23 & 16 & 57,50 & 34,78 \\
\hline Total & 40 & 46 & 100 & 100 \\
\hline
\end{tabular}




\begin{tabular}{|c|c|c|c|c|}
\hline \multirow[b]{2}{*}{ Variáveis } & \multicolumn{4}{|c|}{ Ano de participação no programa } \\
\hline & $\begin{array}{c}2009 \\
(n=40)\end{array}$ & $\begin{array}{c}2010 \\
(n=46)\end{array}$ & $\begin{array}{c}2009 \\
(\%)\end{array}$ & $\begin{array}{c}2010 \\
(\%)\end{array}$ \\
\hline \multicolumn{5}{|c|}{ mAdubaçãons } \\
\hline Sim & 22 & 23 & 55,00 & 50,00 \\
\hline Não & 18 & 23 & 45,00 & 50,00 \\
\hline Total & 40 & 46 & 100 & 100 \\
\hline \multicolumn{5}{|c|}{ nNúmero de vezes que realizou a adubaçãons } \\
\hline 1 & 15 & 15 & 37,50 & 32,61 \\
\hline 2 & 5 & 6 & 12,50 & 13,04 \\
\hline 3 & 2 & 2 & 5,00 & 4,35 \\
\hline Não realizou & 18 & 23 & 45,00 & 50,00 \\
\hline Total & 40 & 46 & 100 & 100 \\
\hline \multicolumn{5}{|c|}{ 'Tipos de adubaçãons } \\
\hline Orgânica & 12 & 15 & 30,00 & 32,61 \\
\hline Mineral & 6 & 5 & 15,00 & 10,87 \\
\hline Ambas & 4 & 3 & 10,00 & 6,52 \\
\hline Não realizou & 18 & 23 & 45,00 & 50,00 \\
\hline Total & 40 & 46 & 100 & 100 \\
\hline \multicolumn{5}{|c|}{${ }^{\text {PTratos culturais de controle de invasoras* }}$} \\
\hline Sim & 37 & 46 & 92,50 & 100 \\
\hline Não & 3 & 0 & 7,50 & 0 \\
\hline Total & 40 & 46 & 100 & 100 \\
\hline \multicolumn{5}{|c|}{ 9Tratos culturais de controle de invasoras*** } \\
\hline Área total & 29 & 26 & 72,50 & 56,52 \\
\hline Entrelinha & 22 & 34 & 55,00 & 73,91 \\
\hline Coramento & 17 & 21 & 42,50 & 45,65 \\
\hline Outro & 0 & 0 & 0,00 & 0,00 \\
\hline Total ${ }^{\#}$ & 68 & 81 & 170,00 & 176,09 \\
\hline \multicolumn{5}{|c|}{ 'Número de vezes que realizou o controle de invasoras* } \\
\hline 0 & 3 & 0 & 7,50 & 0,00 \\
\hline 1 & 7 & 12 & 17,50 & 26,09 \\
\hline 2 & 12 & 14 & 30,00 & 30,43 \\
\hline 3 & 6 & 14 & 15,00 & 30,43 \\
\hline 4 & 9 & 2 & 22,50 & 4,35 \\
\hline 5 & 1 & 3 & 2,50 & 6,52 \\
\hline 6 & 2 & 1 & 5,00 & 2,17 \\
\hline Total & 40 & 46 & 100 & 100 \\
\hline \multicolumn{5}{|c|}{ 'STipo de trato cultural* } \\
\hline Manual & 24 & 26 & 60,00 & 56,52 \\
\hline Mecanizado & 2 & 2 & 5,00 & 4,35 \\
\hline Químico & 9 & 5 & 22,50 & 10,87 \\
\hline Manual e Mecanizado & 0 & 0 & 0,00 & 0,00 \\
\hline Manual e Químico & 2 & 13 & 5,00 & 28,26 \\
\hline Mecanizado e Químico & 0 & 0 & 0,00 & 0,00 \\
\hline Não realizou & 3 & 0 & 7,50 & 0,00 \\
\hline Total & 40 & 46 & 100 & 100 \\
\hline \multicolumn{5}{|c|}{ tDesramans } \\
\hline Sim & 17 & 22 & 42,50 & 47,82 \\
\hline Não & 23 & 24 & 57,50 & 52,17 \\
\hline Total & 40 & 46 & 100 & 100 \\
\hline \multicolumn{5}{|c|}{ "Quantas vezes realizou a desramans } \\
\hline 1 & 13 & 15 & 32,50 & 32,61 \\
\hline 2 & 4 & 6 & 10,00 & 13,04 \\
\hline 3 & 0 & 1 & 0,00 & 2,17 \\
\hline Mais de 3 & 0 & 0 & 0,00 & 0,00 \\
\hline Não realizou & 23 & 24 & 57,50 & 52,17 \\
\hline Total & 40 & 46 & 100 & 100 \\
\hline
\end{tabular}

N = Refere-se ao número de participantes para 2009 e 2010;

$\%$ = Refere-se a razão entre $\mathrm{n}$ da variável em relação ao total; sobre a centena;

\# Respostas múltiplas;

a, b, c, d, e, f, ..., q Indica a variável pesquisada;

${ }^{*} \mathrm{P}<0,01 ; * * \mathrm{P}<0,05 ;{ }^{* * *} \mathrm{P}<0,10$; ns não significativo.

\section{DISCUSSÃO}

A produção florestal neste estudo pode ser caracterizada como de pequena escala, e similar ao conceito de silvicultura em pequena escala adotado em diferentes países (HARRISON et al., 2002; SIMIONI et al., 2018). A silvicultura adotada pelos produtores é realizada com baixo aproveitamento de insumos essencialmente manuais e com mão-de-obra familiar. De acordo com Simioni et al. (2018) isso pode resultar em um baixo custo final, e tornar a atividade potencialmente competitiva a partir do ponto de vista econômico e para um nicho de mercado local. No entanto, os principais desafios que os produtores podem enfrentar estão associados a restrições terra, capital e trabalho (SIMIONI et al., 2018).

O plantio foi realizado, principalmente, em áreas marginais da propriedade, com uma oportunidade muito menor do que as áreas usadas para grãos ou outras atividades. Desta forma, as florestas podem proporcionar biomassa barata que viabiliza atividades que necessitam dessa fonte; além de amenizar a pressão sobre os parcos remanescentes de florestas naturais, possibilitando a melhor utilização da área das propriedades, permitindo a reintegração dessas áreas marginais, mal drenadas ou de topografia mais acidentada, nas quais desempenham importante papel na preservação do solo e dos recursos hídricos (MEHMOOD et al., 2017; SCHUMACHER et al., 2019).

Um grande desafio destacado pelos produtores diz respeito ao uso da terra e dos recursos. Devido à área relativamente pequena, os produtores utilizaram espaçamentos mais denso que o método recomendado para a região. Segundo Farias et al. (2010), isso se deve em parte à falta de cuidados por parte de programas de fomento, nos quais os agentes não divulgam modelos florestais adequados. Portanto, os pequenos produtores acham natural que seus bosques tenham essas características, já que seus vizinhos têm bosques semelhantes.

As operações silviculturais foram realizadas utilizando de trabalho manual e pouco uso de mecanização, onde muitos agricultores usaram apenas mão-de-obra familiar. Em boa parte da operação foram realizadas capinas $e$ 
roçadas manuais para limpeza da área; e coveamento manual no preparo do solo. A produção florestal realizada pelos pequenos produtores sofreu ainda com a falta de recursos, assistência técnica e serviços especializados; o que levou em muitos casos a tomada de decisão baseada na estrutura física e organizacional de outras atividades agrícolas.

A aplicação de matéria orgânica e nutriente ao solo via restos agroindustriais e compostos orgânicos foi a mais citada pelos produtores que realizaram a adubação e ou fertilização. Segundo Agne \& Klein (2014) e Silva et al. (2015) esta é uma prática comum na agropecuária, onde a incorporação de esterco de animais ou outros materiais orgânicos; e as práticas de preparo do solo em condições e tratamentos adequados podem promover efeitos benéficos nos atributos físico-hídricos do solo. A região Sudoeste do Paraná se destaca pela grande produção de frango, no entanto, essa atividade gera grandes quantidades de resíduos ("cama de aviário") (SILVA et al., 2009). Assim, a sua utilização se apresenta como uma das alternativas de maior receptividade pelos agricultores, por estar presente ou disponíveis próximo às propriedades, a um baixo custo (COSTA et al., 2009).

Variações foram encontradas para vistoria, controle de pragas e doenças, técnicas de correção, adubação e fertilização; e na limpeza, desrama e condução florestal. Simioni et al. (2018) destacam algumas diretrizes técnicas adotadas pelas instituições para o plantio de eucalipto, tais como a limpeza da área pré-plantio, preparo do solo, preparação dos furos, controle de formigas 40 e 120 dias antes do plantio; espaçamento de $3 \times 2 \mathrm{~m}$ com adubo básico; fertilização de cobertura em três aplicações: três a seis meses após o plantio, 6 e 12 meses após o plantio e 12 e 24 meses após o plantio. Recomenda-se a limpeza entre linhas de até 18 meses para evitar a concorrência com plantas invasoras. No entanto, os autores (SIMIONI et al., 2018) observaram variação nas técnicas silviculturais adotadas pelos produtores florestais de pequena escala em relação ao recomendado, principalmente no controle de formigas, densidade de mudas, adubação. Outros estudos (FONTES et al., 2003; FARIAS et al., 2010) também verificaram forte variação em relação ao recomendado.

A falta de assistência técnica foi destacada pelos produtores participantes. Assim como, observado para a falta de algumas técnicas silviculturais. A falta de assistência técnica florestal pode influenciar diretamente no insucesso dos (re)florestamentos (FARIAS et al., 2017), além de desmotivação, o que afetaria o número de inscritos no programa. O contato com profissionais, desenvolvendo planos silviculturais, por exemplo, poderia potencialmente aumentar o número de inscritos (WOLDE et al., 2016). Programas e atividades que aumentam o envolvimento dos proprietários de terras com colegas e profissionais da área florestal influenciam fortemente o manejo florestal adotado na propriedade (SNYDER et al., 2019). A associação florestal poderia ser uma vantagem, devido aos benefícios da rede quanto ao acesso às informações silviculturais, de mercado ou de gerenciamento (RIZZO et al., 2019).

Os benefícios econômicos do desenvolvimento florestal são expressos na geração de renda aos produtores participantes, contribuindo para o dinamismo do desenvolvimento local. O fomento florestal também é uma alternativa econômica atraente ao uso de terras ociosas de proprietários não agrícolas. Existe uma adicional geração de renda para produtores rurais de pequeno e médio porte, com a consequente fixação destes em suas terras, reduzindo assim a migração para áreas urbanas (FISCHER \& ZYLBERSZTAJN, 2012). Isso só é possível com uma manutenção da estrutura da terra e qualificação da mãode-obra familiar ao exercício da silvicultura (GONÇALVES et al., 2020).

Como apontam Rochadelli et al. (2008), do ponto de vista das empresas, comparando a área total coberta por micros e pequenas propriedades, em relação aos médios e grandes, a atividade de assistência técnica pode se apresentar como não viável, em termos econômicos. Por outro lado, segundo os autores (ROCHADELLI et al., 2008) a importância social desses grupos é significativa, o que sugere que o poder público poderia investir mais na assistência técnica florestal, concomitantemente à agropecuária. Iniciativas integradas (público-privadas) também são alternativas, visto que esforços em conjunto proporcionariam maior envolvimento e integralização dos produtores a cadeia produtiva.

A inclinação dos micros, pequenos e médios proprietários a permanecerem na atividade via fomento, informações técnicas e de mercado, suas oportunidades e ameaças, bem como a comunicação e integração horizontal, podem representar uma oportunidade de estruturação e fortalecimento do setor florestal no Paraná e no Brasil (ROCHADELLI et al., 2008). Desse modo, reforçase a necessidade de mapear os diversos cenários existentes, os atores, as partes interessadas e os regimes sociotécnicos (SILVEIRA \& JOHNSON, 2016; BONASSA et al., 2018) a fim de elaborar políticas específicas e plataformas modernas de produção florestal.

\section{CONCLUSÕES}


O programa de fomento florestal realizado nos anos de 2009 e 2010 contribuiu para fortalecer a produção florestal de pequena escala, sendo realizada sobretudo por agricultores familiares, fundamentalmente para atender às exigências internas da propriedade e um nicho de mercado local.

As florestas concentram-se nas áreas mais inclinadas, competindo pouco, em área, com a produção de alimentos.

As operações silviculturais foram realizadas utilizando de trabalho manual e pouco uso de mecanização. Os recursos utilizados, bem como os insumos, foram provenientes da propriedade ou disponíveis nas proximidades, a um baixo custo. A produção florestal sofreu com a falta de recursos e serviços especializados; o que levou a tomada de decisão baseada na estrutura física e organizacional de outras atividades agrícolas.

Iniciativas públicas ao reflorestamento constituíram uma ferramenta importante para o desenvolvimento florestal no município, no entanto, devem estar atentas as características individuais de cada participante a fim de melhor formular planos de ação para o programa.

\section{AGRADECIMENTOS}

Os autores agradecem ao Ministério da Educação (Edital Proext), à Prefeitura Municipal de Dois Vizinhos pelo apoio ao projeto e fornecimento de informações sobre o programa de fomento florestal e aos entrevistados, pela ótima recepção e presteza nas informações.

\section{REFERÊNCIAS}

AGNE, S.A.A.; KLEIN V.A. Matéria orgânica e atributos físicos de um Latossolo Vermelho após aplicações de dejeto de suínos. Revista Brasileira de Engenharia Agrícola e Ambiental, v.18, n.7, p.720-726, 2014.

BASSO, V.M. et al. Programas de fomento rural no Brasil. Pesquisa Florestal Brasileira, v.32, n.71, p.321-334, 2012.

BONASSA, G. et al. Scenarios and prospects of solid biofuel use in Brazil. Renewable and Sustainable Energy Reviews, v.82, p.23652378, 2018.

CORDEIRO, S.A. et al. Desempenho do fomento do órgão florestal de Minas Gerais. Cerne, v.15, n.3, p.273-281, 2009.

COSTA, A.M. et al. Potencial de recuperação física de um Latossolo vermelho, sob pastagem degradada, influenciado pela aplicação de cama de frango. Ciência Agrotecnológica, v.33, p.1991-1998, 2009.

COSTA, J.H.C. et al. A survey of management practices that influence production and welfare of dairy cattle on family farms in southern Brazil. Journal of Dairy Science, v.96, n.1, p.307-317,
2013.

EISFELD, R.L. et al. Modelo de fomento florestal nas instituições estaduais nos estados do Sul, São Paulo e Minas Gerais. BIOFIX Scientific Journal, v.2, n.2, p.1-9, 2017.

FARIAS, J.A. et al. Diagnóstico das florestas plantadas na Bacia Hidrográfica do Rio Pardo - RS. Ciência Florestal, v.27, n.1, p.339352, 2017.

FISCHER, A.; ZYLBERSZTAJN, D. O fomento florestal como alternativa de suprimento de matéria prima na indústria brasileira de celulose. Revista Eletrônica de Administração, v.2, p.494-520, 2012.

FONTES, A.A. et al. Análise da atividade florestal no município de Viçosa, MG. Revista Árvore, v.27, n.4, p.517-525, 2003.

GONÇALVES, J.L.M. et al. Forest outgrower schemes in small and medium-sized farmers in Brazil. Forest Ecology and Management, v.456, p.117654, 2020.

HARRISON, S. et al. Non-industrial, smallholder, small-scale and family forestry: What's in a name?. Small-scale Forestry, v.1, n.1, p.1-11, 2002.

KHANAL, P.N. et al. Differences and Similarities Among Members and Nonmembers of Forest Landowner Associations in the Southern United States. Small-scale Forestry, v.19, n.3, p.357$370,2020$.

MARKOWSKI-LINDSAY, M. et al. In forest and intact: Designating future use of family-forest-owned land. Journal of Forestry, v.116, n.4, p.357-366, 2018.

MEHMOOD, M.A. et al. Biomass production for bioenergy using marginal lands. Sustainable Production and Consumption, v.9, p.3-21, 2017.

RIBEIRO, A.B.; MIRANDA, G.M. Estudo descritivo de programas de fomento em empresas florestais. Revista Ambiência, v.5, n.1, p.49-66, 2008.

RIZZO, M. et al. Characterizing small private forests and forest owners' motivations and attitudes in Trentino (Eastern Alps, Italy). Small-scale Forestry, v.18, n.4, p.393-410, 2019.

ROCHADELLI, R. et al. Expansão florestal via fomento no segundo planalto paranaense: uma abordagem a partir da estrutura fundiária das propriedades rurais da região. Cerne, v.14, n.2, p.163-169, 2008.

SCHUMACHER, M.V. et al. Manejo da biomassa e sustentabilidade nutricional em povoamentos de Eucalyptus spp. em pequenas propriedades rurais. Ciência Florestal, v.29, n.1, p.144-156, 2019.

SIMIONI, F.J. et al. Forest biomass chain of production: Challenges of small-scale forest production in southern Brazil. Journal of Cleaner Production, v.174, p.889-898, 2018.

SIQUEIRA, J.D.P. et al. Estudo ambiental para os programas de fomento florestal da Aracruz Celulose S.A. e extensão florestal do Governo do Estado do Espírito Santo. Revista Floresta, p.3-67, 2004. 
SILVA, A.J. et al. Atributos biológico e físico-hídricos de um solo cultivado com eucalipto adubado com cama de frango em Mineiros-GO. Global Science and Technology, v.8, n.3, p.12-20, 2015.

SILVA, C.E.K. et al. Utilização de adubação alternativa na produção de silagem. 3o Seminário: Sistemas de Produção Agropecuária Zootecnia, 2009.

SILVEIRA, S.; JOHNSON, F.X. Navigating the transition to sustainable bioenergy in Sweden and Brazil: lessons learned in a European and International context. Energy Research \& Social Science, v.13, p.180-193, 2016.

SNYDER, S.A. et al. Small-Area Family Forest Ownerships in the USA. Small-scale Forestry, v.18, n.1, p.127-147, 2019.

WOLDE, B. et al. Determinants of enrollment in public incentive programs for forest management and their effect on future programs for woody bioenergy: evidence from Virginia and Texas. Canadian Journal of Forest Research, v.46, n.6, p.775-782, 2016.

Recebido em 21-01-2021 Aceito em 12-04-2021 